\title{
Urban Water Absorbance to Predict Chlorophyll a and Turbidity
}

\author{
Ya-Nan $\mathrm{CAO}^{1, \text { a }}$, Xiu-Hua LI ${ }^{1, b,{ }^{*}, \text { Shao-Dui MA }}{ }^{1, c}$, Jiao-Yan $\mathrm{Al}^{1, \mathrm{~d}}$ and \\ Hong-Xiang $\mathrm{ZHU} \mathrm{U}^{2, \mathrm{e}}$ \\ ${ }^{1}$ College of Electrical Engineering, Guangxi University, Nanning, 530004, China \\ ${ }^{2}$ College of Light Industry and Food Engineering, Guangxi University, Nanning, \\ 530004 , China \\ a529063250@qq.com, ${ }^{b}$ lixh@gxu.edu.cn, ${ }^{c} 1092760690 @ q q . c o m$, \\ daijy@gxu.edu.cn, e'zhxnet@126.com \\ ${ }^{*}$ Corresponding author
}

Keywords: Chlorophyll a, LS-SVM, Spectral absorbance, SVM, Turbidity

\begin{abstract}
This study aimed to use water absorbance in the range of $200-900 \mathrm{~nm}$ to predict the turbidity and chlorophyll a concentration (Chl-a) in urban water. Six kinds of water samples were artificially prepared in this study: spirulina samples (S), chlorella vulgaris samples (C), turbidity samples (T), mixed water samples of S-T, C-T, and S-C. The correlation analysis results showed that the turbidity had a strong correlations with the absorbance at most of the wavelengths, and linear models were built to predict turbidity for each type of water samples, the $R_{v}{ }^{2}$ of each specific model was higher than 0.981 , and the overall $R_{v}{ }^{2}$ reached to 0.955 . For Chl-a prediction, SVM method had better accuracies $\left(R_{v}{ }^{2}>0.986\right)$ for the algae water samples than those $\left(R_{v}{ }^{2}<0.826\right)$ for the turbidity mixed samples. In order to improve Chl-a prediction accuracy for turbidity mixed samples, LS-SVM method was used to estimate Chl-a $\left(R_{v}{ }^{2}>0.987\right)$, which was increased by $31.1 \%$ comparing to the corresponding SVM method. Furthermore, the $R_{v}{ }^{2}$ of the overall Chl-a decoupled model for both S-T and C-T also reached to 0.915. The results showed that the absorbance of unprocessed water samples had great potential to predict Chl-a fast and accurately.
\end{abstract}

\section{Introduction}

Water quality has directed influence on the appearance and functions of urban landscape water which mainly includes natural lakes, artificial lakes, reservoirs, and rivers in the urban area. Most of the urban waters are shallow, small in size, and enclosed or half-enclosed, which makes the maintenance of higher water quality even harder. The parameters of urban water quality with greatest concern are algae amount per unit/ (algae density) and turbidity.

Chlorophyll a (Chl-a) is widely used for evaluate the algae density of water, and spectral absorbance is popularly used for Chl-a estimation. Absorption spectrum of algae represents the competitive ability for light, and also can be used to distinguish different types of algae and concentration. The relationship between the absorption spectrum of algae and the concentration of Chl-a was significant: the absorption spectrum of algae increased gradually with the increasement of Chl-a concentration [1]. In the study of the absorption spectrum of cyanobacteria chlorophyll in polluted waters, the difference between the absorbance value at $436 \mathrm{~nm}$ and $664.5 \mathrm{~nm}$ could be used to predict the Chl-a concentration [2].

Turbidity refers to the degree of obstruction when the light through the water suspended solids, and one of most commonly used methods to detect this parameter is spectrophotometric method. The absorbance of series turbidity standard suspensions were measured, and then the turbidity standard curves for different types of suspensions could be established $[3,4,5,6]$.

Various algorithms have been developed for estimating Chl-a concentration in waters. The threeband algorithm and four-band algorithm based on spectral reflectance of water were often employed to estimate Chl-a concentration [7, 8, 9, 10, 11]. In order to better reduce the effects of suspended particles absorption and backscattering, researchers have also done many studies. For example, the 
unmixing hyperspectral imagery based on support vector nonlinear approximating regression and the Gaussian parameters of Chl-a and suspended sediment based on spectral decomposition were proposed to estimated Chl-a[12,13]. Moreover, the researchers used hyperion data to estimate Chl-a and total suspended solid (TSS) based on the bio-optical model, and then assessed the degree of the Gard lake's eutrophication [14]. For Shitoukoumen Reservoir, the chlorophyll prediction model based on Landsat-TM image data.was established by using GA-PLS method [15].

Tremendous effects have been contributed to predict water chlorophyll content and other major parameters in different water body from spectral reflectance, but the prediction accuracies seldom reached a high level due to the outdoor and open style in the measurement of spectral reflectance. In this research, instead of reflectance, absorbance which can be measured from a relative close environment was suggested to fast and accurately predict Chl-a and turbidity.

\section{Materials and Methods}

\section{Cultivation or Configuration of Water Samples}

(1) Single-factor water samples

Single-factor water sample means the water sample has only one kind of alga or suspension. To simplify the experiment, two most commonly known algae in urban waters were considered in this research: spirulina and chlorella vulgaris. Those two algae were artificially cultivated in laboratory. Two $20 \mathrm{~L}$ experimental water tank were placed beside the window where had sufficient natural light, the temperature held $18-25^{\circ} \mathrm{C}$. The algae seeds were put into those two tanks respectively, and grew for 15 days with supplemental oxygen. Then the spirulina and chlorella vulgaris water samples were acquired to 1) measure Chl-a concentration, 2) dilute to get more water samples with different concentration to measure the absorbance.

The Chl-a concentration of the original water samples was determined by acetonespectrophotometry with Formula (1).

$$
C h l-a=\left[\begin{array}{c}
11.85 \times\left(\mathrm{A}_{664}-\mathrm{A}_{750}\right) \\
-1.54 \times\left(\mathrm{A}_{647}-\mathrm{A}_{750}\right) \\
-0.08 \times\left(\mathrm{A}_{630}-\mathrm{A}_{750}\right)
\end{array}\right] \times V_{1} /\left(V_{2} \times \delta\right)
$$

Where Chl- $a$ represents Chl-a concentration in water sample $(\mu \mathrm{g} / \mathrm{L}) ; \mathrm{A}_{664}, \mathrm{~A}_{647}, \mathrm{~A}_{630}$ and $\mathrm{A}_{750}$ are the absorbance of the extracts at the wavelength of $664 \mathrm{~nm}, 647 \mathrm{~nm}, 630 \mathrm{~nm}$ and $750 \mathrm{~nm}$, respectively. $V_{1}$ is the volume of the acetone extract $(\mathrm{mL}) ; V_{2}$ is the volume of the suction sample $(\mathrm{L}) ; \delta$ is the cuvette optical path $(\mathrm{cm})$.

In order to obtain water samples of different algae concentrations, the original water samples were further diluted based on a certain concentration gradient to obtain spirulina and chlorella vulgaris water samples. All the spirulina and chlorella vulgaris water samples were listed in Table 1. $\mathrm{C}_{1}$ and $\mathrm{C}_{2}$ represent the Chl-a concentration of their original water samples, respectively. 
Table 1 Spirulina water samples and Chlorella vulgaris water samples with different concentrations after dilution process

\begin{tabular}{llllll}
\hline $\begin{array}{l}\text { Spirulina } \\
\text { water } \\
\text { samples }\end{array}$ & $\begin{array}{l}\text { Relative } \\
\text { concentration }\end{array}$ & $\begin{array}{l}\text { Absolute } \\
\text { concentration } \\
{[\mu \mathrm{g} / \mathrm{L}]}\end{array}$ & $\begin{array}{l}\text { Chlorella } \\
\text { vulgaris } \\
\text { water } \\
\text { samples }\end{array}$ & $\begin{array}{l}\text { Relative } \\
\text { concentration }\end{array}$ & $\begin{array}{l}\text { Absolute } \\
\text { concentration } \\
{[\mu \mathrm{g} / \mathrm{L}]}\end{array}$ \\
\hline S0 & $\mathrm{C}_{1}$ & 635.672 & $\mathrm{C} 0$ & $\mathrm{C}_{2}$ & 466.707 \\
S1 & $0.900 \mathrm{C}_{1}$ & 572.105 & $\mathrm{C} 1$ & $0.900 \mathrm{C}_{2}$ & 420.036 \\
S2 & $0.810 \mathrm{C}_{1}$ & 514.894 & $\mathrm{C} 2$ & $0.810 \mathrm{C}_{2}$ & 378.033 \\
S3 & $0.729 \mathrm{C}_{1}$ & 463.409 & $\mathrm{C} 3$ & $0.729 \mathrm{C}_{2}$ & 340.229 \\
S4 & $0.656 \mathrm{C}_{1}$ & 417.064 & $\mathrm{C} 4$ & $0.656 \mathrm{C}_{2}$ & 306.207 \\
S5 & $0.590 \mathrm{C}_{1}$ & 375.358 & $\mathrm{C} 5$ & $0.590 \mathrm{C}_{2}$ & 275.586 \\
S6 & $0.472 \mathrm{C}_{1}$ & 300.286 & $\mathrm{C} 6$ & $0.472 \mathrm{C}_{2}$ & 220.469 \\
S7 & $0.378 \mathrm{C}_{1}$ & 240.229 & $\mathrm{C} 7$ & $0.378 \mathrm{C}_{2}$ & 176.375 \\
S8 & $0.323 \mathrm{C}_{1}$ & 192.183 & $\mathrm{C} 8$ & $0.323 \mathrm{C}_{2}$ & 141.099 \\
S9 & $0.211 \mathrm{C}_{1}$ & 134.528 & & & \\
S10 & $0.127 \mathrm{C}_{1}$ & 80.717 & & & \\
S11 & $0.063 \mathrm{C}_{1}$ & 40.359 & & & \\
\hline
\end{tabular}

Another important kind of one-factor water samples was the samples with different turbidity. Formazine suspension was used to simulate the water turbidity. The suspension was configured by following the polymer formazine turbidity standard (SL 88-2012), which is a water industry standards of China. In the experiment, $5.00 \mathrm{~mL}$ of hydrazine sulfate and $5.00 \mathrm{~mL}$ of hexamethylenetetramine solution were uniformly mixed in a volumetric flask, and then held at $25 \pm 3^{\circ} \mathrm{C}$ for $24 \mathrm{~h}$. The mixed solution was further diluted by adding pure water to the mark line position of $100 \mathrm{~mL}$. This solution was mixed thoroughly to get the standard stock solution which had turbidity of 400 NTU. The standard turbidity suspension of 400 NTU was further diluted several times to obtain water samples with turbidity of $5,10,20,40,80,100,160,200,280$ and 400 NTU, which was recorded as T0-T9.

(2) Two-factor water samples

In order to deeply analyze the absorbance prediction ability in more complicated water samples, three mixed water samples with 2 components were further configured, named two-factor water samples: S-T water samples (70 sample in total) which were cross mixed from spirulina (S5-S11) and turbidity (T0-T9) samples at a 1:1 ratio; C-T water samples (80 sample in total) which were cross mixed from chlorella vulgaris (C0-C7) and turbidity (T0-T9) samples at a 1:1 ratio; S-C water samples (11 sample in total) which were mixed from spirulina samples with concentrations range of 0-317.835 $\mu \mathrm{g} / \mathrm{L}$ (with an interval of $31.784 \mu \mathrm{g} / \mathrm{L}$ ) and chlorella vulgaris samples with concentrations range of $233.355-0 \mu \mathrm{g} / \mathrm{L}$ (with an interval of $23.336 \mu \mathrm{g} / \mathrm{L}$ ).

\section{Spectral Absorbance Measurement}

Different water samples were thoroughly mixed before transferring to quartz cells for their measurement of spectral absorbance. The optical length of the quartz cell was $1 \mathrm{~cm}$. The absorbance of each water sample was measured by Shimadzu UV-VIS spectrophotometer UV-2600 with a spectral interval of $0.5 \mathrm{~nm}$, and the spectral range was 200-900 nm.

\section{Methods}

The correlations between absorbance and different components were firstly analyzed, and sensitive wavelengths were selected, and then the selected bands were denoised with wavelet transform method, 2 abnormal samples were removed. Cross-validation was used to build and evaluate the prediction models for each group of water samples. Linear models were built to predict turbidity for each group of samples which included turbidity because of the strong correlation between turbidity and absorbance found at the sensitive wavelength. Then, SVM method was further adopted to estimate Chl-a concentration for each group of samples. In order to improve the Chl-a prediction 
accuracy for turbidity mixed samples, LS-SVM method was used by adding the predicted turbidity from previous linear model as the input variable.

\section{Results and Discussion}

\section{Correlations between Spectral Absorbance and Chl-a\&turbidity}

The correlations between absorbance and each component in both single-factor and two-factor water samples were analyzed, the results are shown in Fig.1 and Fig.2. Fig.1 represents the correlations between the single factor and absorbance in the single-factor samples, and Fig.2 is the correlations between Chl-a/turbidity and the absorbance in the two-factor samples.

As can be seen from Fig.1: a) For single-factor samples, the correlation between absorbance and turbidity remained stable throughout the measured spectral range, and the correlation coefficient $(R)$ was close to $1 ; \mathrm{b})$ the absorbance of chlorella vulgaris water samples also had a stable and significant correlation with Chl-a except for the wavelengths near $232 \mathrm{~nm}$, and the maximum correlation coefficient $(0.999)$ was obtained at $240 \mathrm{~nm}$; c) the correlation curve of spirulina water samples absorbance and Chl-a concentration fluctuated greatly in $200-500 \mathrm{~nm}$, and gradually stabilized within the range of $650-900 \mathrm{~nm}$, and the highest $R$ was reached at $237.5 \mathrm{~nm}$, which was 0.996.

Fig.2 shows that: a) For the mixed water samples, such as S-T and C-T samples, Chl-a had completely opposite correlation trends with absorbance, comparing to the correlation trends between turbidity and absorbance; b) the wavelength around $237 \mathrm{~nm}$ is the maximum correlation of Chl-a and absorbance, but also the minimum correlation between turbidity and absorbance; c) the $R$ of turbidity and absorbance at $680 \mathrm{~nm}$ was above 0.98 ; d) for the most range of the waveband, the correlations between Chl-a and absorbance were not significant, the $R$ was less than 0.2 .

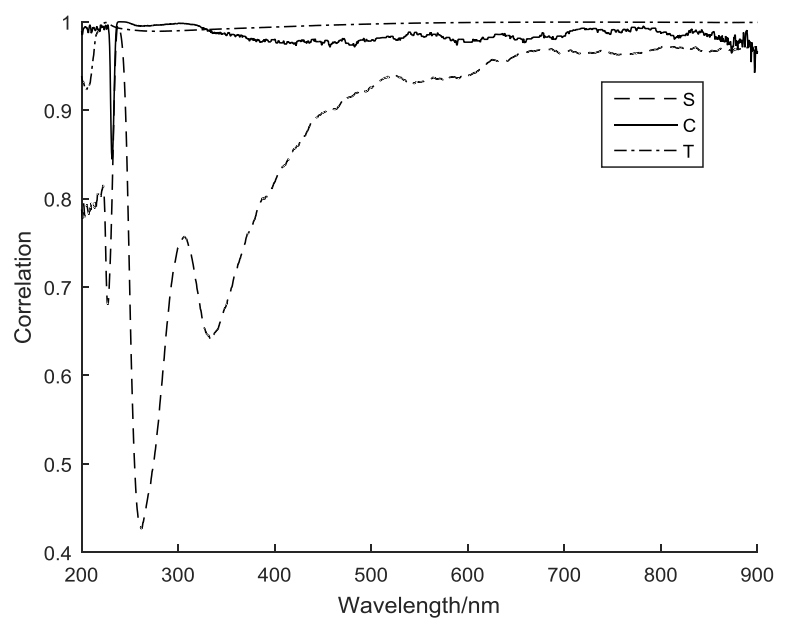

Fig. 1 Correlation analysis of different factors and absorbance in single-factor water samples 


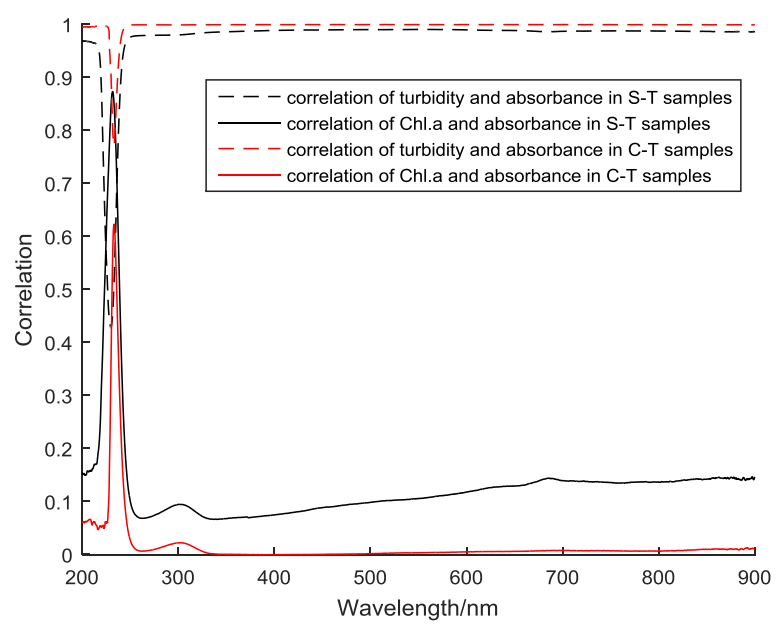

Fig. 2 Correlation analysis of different factors and absorbance in two-factor water samples

The band near $675 \mathrm{~nm}$ was characteristic absorption peak of Chl-a, and had a significant relationship with other bands [16]. Based on the turbidity standard curve, there was an obvious linear relationship between turbidity and spectral absorbance at $680 \mathrm{~nm}$. Therefore, $680 \mathrm{~nm}$ was selected as one of the sensitive band. The other band was $237 \mathrm{~nm}$, at which the correlation changed greatly, such as the $R$ was only 0.750 in the S-T samples, while the $R$ was up to 0.993 in the T samples.

\section{Different Predictions Models}

(1) Turbidity prediction models

In order to simplify the turbidity prediction model, only linear models at $680 \mathrm{~nm}$ were built to predict turbidity for each sample type. The linear regression models are shown in Table 2, where $y$ is the turbidity of different water sample types, and $x$ is the absorbance of different water sample types. As can be seen in Table 2, different models were acquired for different type of water sample, the $R_{v}{ }^{2}$ of them were higher than 0.981 , but different models would also bring troubles in application, so an overall model (last column) for all type of the water samples was also built, and the $R_{v}{ }^{2}$ reached to 0.955 , showed a good potential for further application.

Table 2 Linear regression models to predict turbidity

\begin{tabular}{lllllll}
\hline Samples & $\begin{array}{l}\text { Sample } \\
\text { numbers }\end{array}$ & $\begin{array}{l}\text { Validation } \\
\text { method }\end{array}$ & Turbidity model & $R_{v}{ }^{2}$ & $R M S E$ & $\begin{array}{c}p- \\
\text { value }\end{array}$ \\
\hline $\mathrm{T}$ & 10 & $\begin{array}{l}\text { three-fold cross- } \\
\text { validation } \\
\text { seven-fold cross- }\end{array}$ & $y=285.534 x+1.360$ & 0.999 & 3.026 & 0 \\
$\mathrm{~S}-\mathrm{T}$ & 70 & $\begin{array}{l}\text { validation } \\
\text { six-fold cross- } \\
\text { validation }\end{array}$ & $y=262.256 x-33.129$ & 0.981 & 7.978 & 0 \\
$\mathrm{C}-\mathrm{T}$ & 78 & $\begin{array}{l}\text { three-fold cross- } \\
\text { validation }\end{array}$ & $\mathrm{y}=260.3792 \mathrm{x}-15.398$ & 0.955 & 14.255 & 0 \\
$\begin{array}{l}\text { T\&S- } \\
\text { T\&C-T }\end{array}$ & 158 & & & 0.997 & 2.458 & 0 \\
\hline
\end{tabular}

(2) Chl-a prediction model

Firstly, SVM method was used to predict the Chl-a concentration for different water sample types, and the prediction models were listed in Table 3. As can be seen from the Table 3, for algae water samples, the $R_{v}{ }^{2}$ of the Chl-a model was greater than 0.98. But when the water samples contained algae and suspended solid, the $R_{v}{ }^{2}$ was reduced to 0.753 and 0.826 . This also showed that the addition of turbidity has a significant impact on the Chl-a concentration in the absorbance, suggesting a coupling relationship between Chl-a concentration and turbidity was existed. 
Table 3 Chl-a model established by SVM method

\begin{tabular}{|c|c|c|c|c|c|c|}
\hline Samples & $\begin{array}{l}\text { Sample } \\
\text { numbers }\end{array}$ & Validation method & predictor & $R_{v}^{2}$ & $R M S E$ & $\begin{array}{c}p- \\
\text { value }\end{array}$ \\
\hline S & 12 & $\begin{array}{l}\text { three-fold cross- } \\
\text { validation }\end{array}$ & Chl-S & 0.993 & 0.254 & 0.016 \\
\hline $\mathrm{C}$ & 9 & $\begin{array}{l}\text { three-fold cross- } \\
\text { validation }\end{array}$ & Chl-C & 0.991 & 0.460 & 0.021 \\
\hline S-T & 70 & $\begin{array}{l}\text { seven-fold cross- } \\
\text { validation }\end{array}$ & Chl-S & 0.753 & 0.185 & 0.001 \\
\hline $\mathrm{C}-\mathrm{T}$ & 78 & $\begin{array}{l}\text { six-fold cross- } \\
\text { validation }\end{array}$ & Chl-C & 0.826 & 0.201 & 0.002 \\
\hline \multirow[t]{3}{*}{$\mathrm{S}-\mathrm{C}$} & \multirow[t]{3}{*}{11} & \multirow{3}{*}{$\begin{array}{l}\text { three-fold cross- } \\
\text { validation }\end{array}$} & Chl-S & 0.986 & 0.235 & 0.006 \\
\hline & & & Chl-C & 0.986 & 0.153 & 0.005 \\
\hline & & & total Chl-a & 0.988 & 0.150 & 0.003 \\
\hline
\end{tabular}

There was no obvious absorption peak in the visible region for T-mixed samples comparing to Texcluded samples, but the peak was obvious in the ultraviolet region the reason for this could be the high turbidity [17]. In order to further study the influence of turbidity on Chl-a concentration, SVM model for $\mathrm{S}$ water samples was directly used in S-T water samples to predict its Chl-a concentration. A data set which had same Chl-a concentration $(20.179 \mu \mathrm{g} / \mathrm{L})$ but different turbidity were selected out to compare their measured Chl-a and predicted Chl-a values, and it found that the turbidity led to an increase in the Chl-a prediction. The effects of turbidity on the chlorophyll absorbance included two aspects, one is the suspended solid can absorb some of the light, and the other is the suspended solid can reflect back the light which could also reduce the light at the receive end. The absorb ability of turbidity is nearly a linear trend as shown in Table 2 . Therefore, the influence of turbidity was positively correlated with the chlorophyll concentration. In order to further improve the Chl-a prediction accuracy for turbidity mixed samples, LS-SVM method was used to build Chla decoupled models by adding the predicted turbidity which calculated from the previous linear model as the input variable. The models were shown in the Table 4.

Table 4 The Chl-a decoupled models with LS-SVM method for mixed water samples with turbidity

\begin{tabular}{lllllll}
\hline Samples & Sample & Validation method & predictorr & $R_{v}{ }^{2}$ & $R M S E$ & $p$-value \\
\hline S-T & 70 & $\begin{array}{l}\text { seven-fold cross- } \\
\text { validation }\end{array}$ & Chl-a & 0.987 & 5.643 & 0 \\
C-T & 78 & $\begin{array}{l}\text { six-fold cross- } \\
\text { validation } \\
\text { four-fold cross- } \\
\text { validation }\end{array}$ & Chl-a & 0.993 & 3.684 & 0 \\
S-T\&C-T & 148 & Chl-a & 0.915 & 15.625 & 0 \\
\hline
\end{tabular}

Comparing the Chl-a prediction models in Table 3 and 4, it can be seen that the $R_{v}{ }^{2}$ of Chl-a decoupled model for S-T and C-T reached to 0.987 and 0.993 , which were increased by $31.1 \%$ and $20.2 \%$, respectively. The results indicated that the decoupled models had greater potential to predict Chl-a concentration. And another overall decoupled model for both S-T and C-T was also built to try to predict Chl-a concentration for unknown water type.

\section{Conclusions}

In this study, 6 types of water samples were artificially prepared in this study: spirulina samples (S), chlorella vulgaris samples $(\mathrm{C})$, turbidity samples $(\mathrm{T})$ and three mixed water samples of S-T, C-T, SC. Efforts were made to predict $\mathrm{Chl}-\mathrm{a}$ concentration and turbidity from water absorbance. The correlations between absorbance and Chl-a \& turbidity were firstly analyzed, and then the sensitive 
bands were selected. Linear, SVM and LS-SVM method were adopted to build prediction models for turbidity and Chl-a concentration. The main findings were summarized as follows:

1) Whether in the single-factor water samples, or in two-factor water samples, turbidity always had a great correlation with water absorbance. Linear models were built for both specific type of water samples and all the water samples, the $R_{v}{ }^{2}$ of specific model was higher than 0.981 and the overall $R_{v}{ }^{2}$ was reached to 0.955 .

2) For algae water samples, Chl-a concentration had relative lower correlation with absorbance, therefore, SVM method was used for Chl-a prediction, and the $R_{v}{ }^{2}$ were higher than 0.986 .

$3)$ In the mixed water samples containing both algae and suspended solids, the accuracies of SVM model $\left(R_{v}{ }^{2}<0.826\right)$ were lower than the algae water samples because of the interaction effect between Chl-a and turbidity, so LS-SVM method was used to build Chl-a decoupled models by adding the predicted turbidity as the input variables. The $R_{v}{ }^{2}$ of the decoupled model reached to 0.987 and 0.993 for turbidity mixed water samples, which were increased by $31.1 \%$ and $20.2 \%$ comparing to the corresponding SVM method. Furthermore, the $R_{v}{ }^{2}$ of the overall decoupled model for unknown water type also reached to 0.915 , indicating an good potential for application.

The results showed that the absorbance of unprocessed water samples had great potential to predict Chl-a fast and accurately. But more efforts should be done to consider more water types which include more components, such as S-C-T, and more universe model should be further explored to apply in natural urban water with unknown components.

\section{Acknowledgment}

This study was financially supported by Guangxi Natural Science Foundation (No.2015GXNSFBA139261), National Natural Science Foundation of China (No.31401290, No.31760342) and Guangxi Projects for Science and Technology (No.14251009).

\section{References}

[1] H.L. Zhou, J.H. Zhu, B. Han, T.J. Li, A.A. Yang, Comparison of spectral absorption characteristics of several typical algale, Ocean Technology. 29.3 (2010), 78-81.

[2] Z.M. Zhao, X.Q. Hong, P. Li, X.D. Jin, Spectral analysis of cyanobacteria chlorophyll in polluted water, Spectroscopy \& Spectral Analysis. 30.6 (2010) 1596.

[3] Y.Y. Zhao, B.J. Shen, J.L. Hu, J.P. Zhao: submitted to Chinese Society For Environmental Sciences (2013).

[4] J.H. Liu, Fluorescence spectrophotometric determination of chlorophyll content of the impact of factors. Diss. Hebei University of Science and Technology, (2014).

[5] P.Y. Lv, J.S. Cui, L.L. Duan, Effect of turbidity on fluorescence intensity of chlorophyll-a in water, Procemical Analysis-Chemical Class. 51.6 (2015) 741-744.

[6] M.H. Zheng 2016 Variation of in vivo fluorescence during diatom growth and its effect on chlorophyll measurement, Diss. China University of Geosciences, (2016).

[7] D. Giorgio, A.A. Gitelson, D.C. Rundquist, Towards a unified approach for remote estimation of chlorophyll-a in both terrestrial vegetation and turbid productive waters, Geophysical Research Letters. 30.18 (2003) 159-171.

[8] P.V. Zimba, A. Gitelson, Remote estimation of chlorophyll concentration in hyper-eutrophic aquatic systems: model tuning and accuracy optimization, Aquaculture. 256 (2006) 272-286.

[9] A.A. Gitelson, G. Dall'Olmo, W. Moses, D.C. Rundquist, T. Barrow, T.R. Fisher, A simple semi-analytical model for remote estimation of chlorophyll-a in turbid waters: validation, Remote Sensing of Environment. 112.9 (2008) 3582-3593. 
[10] W.J. Moses, A.A. Gitelson, S. Berdnikov, V. Saprygin, V. Povazhnyi, Operational merisbased NIR-red algorithms for estimating chlorophyll-a, concentrations in coastal waters-the Azov sea case study. Remote Sensing of Environment. 121.138 (2012) 118-124.

[11] C.F. Le, Y.M. Li, Z. Yong, D.Y. Sun, C.C. Huang, H. Lu, A four-band semi-analytical model for estimating chlorophyll a in highly turbid lakes: the case of Taihu Lake, China, Remote Sensing of Environment. 113.6 (2009) 1175-1182.

[12] B. Wu, L.P. Zhang, P.X. Li, Unmixing hyperspectral imagery based on support vector nonlinear approximating regression, Journal of Remote Sensing. 10.3 (2006) 312-318.

[13] C. Cheng, Y. Wei, J. Xu, Z. Yuan, Remote sensing estimation of chlorophyll a and suspended sediment concentration in turbid water based on spectral separation, Optik-International Journal for Light and Electron Optics. 124.24 (2013) 6815-6819.

[14] C. Giardino, V.E. Brando, A.G. Dekker, N. Strömbeck, G. Candiani, Assessment of water quality in Lake Garda (Italy) using hyperion, Remote Sensing of Environment. 109.2 (2007) 183195.

[15] K. Song, D. Lu, L. Li, S. Li, Z. Wang, J. Du 2012 Remote sensing of chlorophyll-a, concentration for drinking water source using genetic algorithms (GA)-partial least square (PLS) modeling, Ecological Informatics. 10.7 (2012) 25-36.

[16] C.D. Mobley, Light and Water: Radiative Transfer in Natural Waters, Academic Press, SanDiego, 1994.

[17] Z.F. Qiu, J.W. Tang, Y.J. He, Absorption characters of waters in the high frequency red tides areas of theEast China sea. Studia Marina Sinica. 48 (2007) 6-19

[18] Y.H. Huang, D. Jiang, D.F. Zhuang, J.Y. Fu, Evaluation of hyperspectral indices for chlorophyll-a concentration estimation in Tangxun Lake (Wuhan, China), International Journal of Environmental Research \& Public Health, 7.6 (2010) 2437-2451.

[19] X. Liu, J. Liu, Study on soil available N and available K based on near infrared spectroscopy using LS-SVM modeling method, Spectroscopy and Spectral Analysis, 32.11 (2012) 3019-3023.

[20] C. Le, C. Hu, J. Cannizzaro, D. English, F. Muller-Karger, Z. Lee, Evaluation of chlorophyll-a remote sensing algorithm for an optically complex estuary, Remote Sensing of Environment, 129.2 (2013) 75-89. 